\title{
BRIEF

\section{Using the Objective Structured Teaching Ecounter to Assess Resident Teaching Skills}

Sangrok Oh, DO, MS; Timothy Servoss, PhD; Diana Wilkins, MD

\begin{abstract}
BACKGROUND AND OBJECTIVES: Residents are often the primary educators for medical students during their clinical years. Residency training programs are therefore responsible for providing resident educator training. This, in turn, requires an assessment tool to ensure residents demonstrate the knowledge, skills, and behaviors required for their teaching responsibilities. To this end, a rating scale was developed and applied during an objective structured teaching encounter (OSTE). The purposes of this study were to gather qualitative impressions of family medicine residents regarding participation in the OSTE and reliability evidence for the OSTE instrument.
\end{abstract}

METHODS: All 41 family medicine residents participated in the study. Prior to the OSTE, residents received instruction on the five microskills clinical teaching model. Medical students assisted as standardized learners for the encounter and faculty served as assessors. We conducted focus groups to solicit resident feedback.

RESULTS: Residents demonstrated evidence of the five microskills. Feedback on the OSTE process from the interns was positive, noting that the experience helped increase their confidence to teach, as well as provided a useful method to practice a teaching strategy. The assessment tool evidenced good internal consistency and interrater reliability.

CONCLUSIONS: The OSTE is an easy-to-implement and reliable method for resident educator skill assessment that left residents feeling more confident and better equipped to give constructive feedback during teaching encounters.

(Fam Med. 2021;53(6):453-6.)

doi: 10.22454/FamMed.2021.980882

$\mathbf{R}$ esidents play a critical role in educating clerkship students, and residency programs must ensure residents are prepared to effectively teach. Training residents to become educators is of growing interest in graduate medical education, ${ }^{1}$ and the family medicine training requirements from Accreditation Council for Graduate Medical Education idents.
The objective structured teaching encounter (OSTE) is a tool used for providing formative assessment of teaching skills. ${ }^{3-5}$ Traditionally utilized in faculty development, its use to train residents and fellows has been previously described ${ }^{6-9}$ This study represents a first examination of the application of the OSTE to family medicine residents. The purposes of this study were to gather the qualitative impressions of family medicine interns regarding how the OSTE influenced their thoughts or feelings about teaching, and to gather reliability evidence for this OSTE rating scale.

\section{Methods}

Forty-one family medicine residents participated in the OSTE. Ten interns participated in the focus groups. Prior to the OSTE, faculty raters, residents, and medical students serving as standardized learners underwent training. To provide a framework for teaching in the OSTE encounter, residents received instruction on the five microskills. ${ }^{10}$ Because time is a significant obstacle to clinical teaching, ${ }^{11,12}$ this approach was chosen due to its time-efficiency. demonstrate competence in: educating patients, families, students, residents, and other health professionals." However, residents' teaching skills are rarely assessed, and no standardized assessment tool has been applied to family medicine res-
From the University at Buffalo Jacobs School of Medicine and Biomedical Sciences, Buffalo, NY (Drs Oh and Wilkins); Department of Psychology, Canisius College, Buffalo, NY (Dr Servoss); Department of Family Medicine at University at Buffalo, Buffalo, NY (Drs Oh and Wilkins). 
Residents read a paper on the five microskills ${ }^{13}$ and a PowerPoint presentation that provided detailed explication of each of the microskills, augmented with video demonstrations. Five faculty raters met for 1 hour as a group to review a sample case video, practice completion of the assessment form, and compare/ discuss ratings. Six standardized learners underwent 1 hour of training that consisted of background on the purpose of an OSTE, explanation of the five microskills, watching a sample case video, and rehearsal of the case script. Students received a $\$ 50$ gift card for their role as standardized learners. All training sessions were facilitated by one of the authors of this study who has experience in assessment and faculty development. Training materials/case script are available online at the STFM Resource Library,${ }^{10}$ or directly from the authors.

Each live OSTE encounter simulated a precepting experience where the standardized learner presented a patient case about hyperthyroidism ${ }^{14}$ to the resident. As the resident responded to the scripted queries from the standardized learner, the faculty rater observed the educational interaction between the resident and the standardized learner. After each encounter, faculty had 5 minutes to complete the assessment form and provide residents with feedback on their performance. Encounters were videotaped and each was reviewed by a second faculty rater to examine agreement between raters.

The rating form was developed from resources published by Elizabeth Morrison on MedEdPORTAL and a tool developed by the Shapiro Institute at Harvard Medical School..$^{15}$ In addition to seven items designed to measure general teaching behaviors, we included five items targeting the five microskills.

We used descriptive statistics to capture resident performance on the instrument. We used Cronbach $\alpha$ to characterize the internal consistency reliability of the instrument and percent agreement; we used weighted $\mathrm{k}^{16}$ and intraclass correlation to quantify interrater reliability.

We conducted two separate, nonsequential focus groups to assess the interns' perceptions of the OSTE (see STFM Resource Library for focus group questions). To ensure that residents felt comfortable providing honest feedback, a researcher unaffiliated with the residency program conducted semistructured, open-ended focus groups, taking field notes and audio recording the sessions. No residency faculty were present.

We provided deidentified digital transcriptions of the recordings from a third-party transcribing service to two investigators for analysis. We conducted a thematic analysis of the transcription and fields notes utilizing immersion-crystallization. ${ }^{17}$ The investigators reviewed the key themes to verify consistency and validity of interpretations. The University of Buffalo Institutional Review Board deemed the study to be Not Human Research (STUDY00003216).

\section{Results}

Residents generally demonstrated evidence of the five microskills and other behaviors related to creating a supportive learning environment while being less proficient at encouraging self-direction and input from the standardized medical students. Table 1 shows performance.

Analysis of the focus group data yielded six emergent themes. Themes and illustrative quotations are shown in Table 2.

Internal consistency reliability was good ( $\alpha=.77[.65, .86])$, as was interrater reliability. Out of the 492

Table 1: Faculty Ratings of Resident Performance ( $\mathrm{N}=41)$

\begin{tabular}{|c|c|c|c|c|}
\hline \multirow[t]{2}{*}{ Criteria For Evaluation } & Evidence & $\begin{array}{l}\text { Emerging } \\
\text { Evidence }\end{array}$ & No Evidence & \multirow[t]{2}{*}{ Mean $^{\mathrm{a}}$ (SD) } \\
\hline & n (\%) & n (\%) & n (\%) & \\
\hline Models professionalism & $40(97.6)$ & $1(2.4)$ & $0(0.0)$ & $2.98(.16)$ \\
\hline Demonstrates enthusiasm for teaching & $30(73.2)$ & $10(24.4)$ & $1(2.4)$ & $2.71(.51)$ \\
\hline Encourages learner to ask questions & $19(46.3)$ & $12(29.3)$ & $10(24.4)$ & $2.22(.82)$ \\
\hline Asks learner to make a commitment & $38(92.7)$ & $3(7.3)$ & $0(0.0)$ & $2.93(.26)$ \\
\hline Probes the learner for supporting evidence & $35(85.4)$ & $5(12.2)$ & $1(2.4)$ & $2.83(.44)$ \\
\hline Teaches the learner a relevant topic & $33(80.5)$ & $7(17.1)$ & $1(2.4)$ & 2.78(.47) \\
\hline Provides positive feedback & $32(78.0)$ & $6(14.6)$ & $3(7.3)$ & $2.71(.60)$ \\
\hline Corrects mistakes & $26(63.4)$ & $7(17.1)$ & $8(19.5)$ & $2.44(.81)$ \\
\hline Maintains good eye contact & $39(95.1)$ & $2(4.9)$ & $0(0.0)$ & $2.95(.22)$ \\
\hline Leads an organized discussion & $26(63.4)$ & $13(31.7)$ & $2(4.9)$ & $2.59(.59)$ \\
\hline Encourages self-directed learning & $5(12.2)$ & $2(4.9)$ & $34(82.9)$ & $1.29(.68)$ \\
\hline Encourages self-reflection & $1(2.4)$ & $1(2.4)$ & $39(95.1)$ & $1.07(.35)$ \\
\hline
\end{tabular}

a Items were scored such that "evidence" $=3$, "emerging evidence" $=2$, and "no evidence" $=1$. The shaded items represent the five microskills. 
Table 2: Interns' Impressions of the OSTE Process

\begin{tabular}{|c|c|}
\hline Theme & Quote \\
\hline $\begin{array}{l}\text { Helped to boost } \\
\text { comfort/confidence } \\
\text { with teaching }\end{array}$ & $\begin{array}{l}\text { "I felt really apprehensive about teaching. I don't like it. So I think then doing the OSTE and then } \\
\text { also getting positive feedback made me feel ready for the role and ready to help students.... So, I } \\
\text { like the OSTE for that purpose." } \\
\text { "Once you heard some good feedback, it was like, 'Okay, this is something I can continue to do,' and } \\
\text { you had confidence to try and do it." }\end{array}$ \\
\hline $\begin{array}{l}\text { Helped validate their } \\
\text { teaching ability }\end{array}$ & $\begin{array}{l}\text { "My teaching experience in the past was more in a classroom setting .......... so I think it was good } \\
\text { to have pointers of how... to teach clinically rather than just regurgitating facts and information. } \\
\text { So it was useful." } \\
\text { "I also feel like it's more of a validation. I really liked it before, I still like it now. I still want to do } \\
\text { it. I'm on a rotation now where it's really my first time working with medical students as a resident } \\
\text { and I'm really enjoying it, so yeah, it's a validation, I guess." }\end{array}$ \\
\hline $\begin{array}{l}\text { Gave them a tool } \\
\text { which provided } \\
\text { structure to their } \\
\text { teaching and } \\
\text { learning }\end{array}$ & $\begin{array}{l}\text { "It definitely gave me a little bit more structure or organization of my thoughts when going } \\
\text { forward.... I appreciated that structure, I think it'll just take some practice but it was helpful." } \\
\text { "I feel like when someone else is teaching me, I can see them following the structure now that we } \\
\text { learned. So I notice that a lot more now and it actually helps reinforce when it does come time for } \\
\text { us to teach the students." }\end{array}$ \\
\hline $\begin{array}{l}\text { Helped them give } \\
\text { better feedback }\end{array}$ & $\begin{array}{l}\text { "I definitely liked the feedback on how to maybe give... The best way to give constructive criticism } \\
\text { because it's something I've always.... struggled with, how to not sound harsh but ...... correct the } \\
\text { students. I thought that part was very helpful." } \\
\text { "Pointing out what they did well before the criticism is something I don't feel like I did quite } \\
\text { enough before, so I think it was good to be reminded of why it's important." }\end{array}$ \\
\hline $\begin{array}{l}\text { Ambivalence } \\
\text { about changes } \\
\text { in motivation in } \\
\text { teaching }\end{array}$ & $\begin{array}{l}\text { "It was a good experience... But would I sign up to do it? Probably not. Why wouldn't I? Because } \\
\text { I like when it's organic. I don't like setting up lecture plans because I feel like teaching should be } \\
\text { more of a conversation. So if somebody has a question about something or they research a topic, } \\
\text { and I have information on it, then I'll be able to give that to you. But if I have to go on a structured } \\
\text { lesson plan, I tend to not like doing it like that." }\end{array}$ \\
\hline $\begin{array}{l}\text { Mixed enthusiasm } \\
\text { for further education } \\
\text { in teaching theory }\end{array}$ & $\begin{array}{l}\text { "If you're interested in academic medicine, I think that would be good for someone who is." } \\
\text { "No, yeah, 'cause even..., we rotate with students all the time. And they're like a part of the team, } \\
\text { so you hope that you're giving them some education while they're there, because people are paying } \\
\text { to be there, so I think it's gonna be beneficial for us to get those skills, even if you don't wanna do } \\
\text { academics after you're done." }\end{array}$ \\
\hline
\end{tabular}

Abbreviation: OSTE, objective structured teaching encounter.

total ratings (41 residents: 12 items), raters exactly agreed 396 times $(80 \%)$. Of the 96 disagreements, the ratings were within one scale point 83 times. Weighted $\kappa$ was $.71(.65$, $.77)$, and the intraclass correlation was $.82(.66, .90)$ indicating substantial agreement.

\section{Discussion}

Analysis of the OSTE data revealed that family medicine residents were capable of demonstrating favorable teaching behaviors while benefitting from participation in the assessment process. The OSTE provided residents with an opportunity to put their teaching skills into action and receive feedback on them, something that is not feasible when mere instruction in teaching skills is offered without an applied assessment process. The formative feedback residents received helped them feel more validated, confident, and better equipped to give constructive feedback to others during future teaching encounters.

Psychometric analyses revealed good internal consistency and interrater reliability. Statistical measures of interrater agreement in this study are comparable to those found by Zakoff et $\mathrm{al}^{3}$ with pediatric residents, suggesting that different faculty raters are able to apply the rating scale in a consistent fashionan important consideration for programs considering implementation of an OSTE.

That only interns were able to participate in the focus groups represents a limitation of the qualitative data and the conclusions that may be drawn from them. It is possible that the benefits to teaching confidence reported by the interns would not generalize to residents in later program years who have had more applied teaching experience. If this is the case, however, the observation that participation in the OSTE is beneficial for residents who are just beginning their clinical teaching remains an important finding.

Another limitation of this study is the lack of follow-up data. For example, although participants demonstrated teaching skills and reported a boost in teaching confidence in the short term, there is no evidence to suggest that these would be sustained indefinitely. Recent research by Zakoff et $\mathrm{al}^{3}$ suggests that OSTEs are an appropriate approach for 
documenting longitudinal change in resident teaching behaviors.

Despite these limitations, this study represents the first application of an OSTE to family medicine residents using a reliable assessment tool. It is a promising approach for programs interested in assessing their residents' teaching skills in accordance with ACGME standards, and provides useful formative feedback to bolster residents' comfort in teaching.

ACKNOWLEDGMENTS: The authors gratefully acknowledge the comments and suggestions of Christina Padgett, DO, Marlon Koenigsberg, $\mathrm{PhD}$, Denise McGuigan, MSEd, Masashi Ohira, MD, Bridgett Forshee, MS, Ranjit Singh, $\mathrm{MD}$, and Karen Zinnerstrom $\mathrm{PhD}$.

The OSTE Assessment Tool was adapted from the Peer Observation Tool Developed by the Shapiro Institute for Education and Research at HMS and BIDMC.

FINANCIAL SUPPORT: This project is supported by the Health Resources and Services Administration (HRSA) of the US Department of Health and Human Services (HHS) under grant number K02HP30819, "Primary Care Medicine and Dentistry Clinician Educator Career Development Award." Award amount: $\$ 200,000$. This information or content and conclusions are those of the author and should not be construed as the official position or policy of, nor should any endorsements be inferred by HRSA, HHS or the US Government.

PRESENTATIONS: This project was presented as "So You Think You Can Teach?", a poster presentation at Family Medicine Education Consortium, in Rye Brook, New York, 2018.
CORRESPONDING AUTHOR: Address correspondence to Dr Sangrok Oh, University at Buffalo Family Medicine, 77 Goodell St, Suite 240, Buffalo, NY 14203. Sroh@buffalo.edu.

\section{References}

1. Bree KK, Whicker SA, Fromme HB, et al Residents-as-teachers publications: what can programs learn from the literature when starting a new or refining an established curriculum? J Grad Med Educ. 2014;6(2):237-248 doi:10.4300/JGME-D-13-00308.1

2. ACGME Program Requirements for Graduate Medical Education in Family Medicine. 2020:26.

3. Zackoff M, Jerardi K, Unaka N, Sucharew $\mathrm{H}$, Klein M. An observed structured teaching evaluation demonstrates the impact of a resident-as-teacher curriculum on teaching competency. Hosp Pediatr. 2015;5(6):342-347. doi:10.1542/hpeds.2014-0134

4. Trowbridge RL, Snydman LK, Skolfield J, Hafler J, Bing-You RG. A systematic review of the use and effectiveness of the Objective Structured Teaching Encounter. Med Teach. 2011;33(11):893-903. doi:10.3109/014215 9X.2011.577463

5. Siddiqui T, Ahmed A. Reliability of OSTE in the health professions education exit examination of college of physicians and surgeons, Pakistan: a psychometric analysis. J Coll Physicians Surg Pak. 2013;23(1):62-66.

6. Boillat M, Bethune C, Ohle E, Razack S, Steinert Y. Twelve tips for using the objective structured teaching exercise for faculty development. Med Teach. 2012;34(4):269-273. doi:1 0.3109/0142159X.2011.599891

7. Sturpe DA, Schaivone KA. A primer for objective structured teaching exercises. Am J Pharm Educ. 2014;78(5):104. doi:10.5688/ ajpe785104
8. Miloslavsky EM, et al. Assessing rheumatology fellows' teaching skills using the objective structured teaching exercise (OSTE). Arthritis Rheumatol. 2014;66:S1261.

9. Louis D, Garcia C. Developing an observed structured teaching examination for dermatology residents at OUHSC. J Am Acad Dermatol. 2011;64(2):AB80.

10. Oh TS, Wilkins D. Using the Objective Structured Teaching Encounter to Assess Resident Teaching Skills. Retrieved from the STFM Resources library. Published 2021. https:// resourcelibrary.stfm.org/viewdocument/ using-the-objective-structured-teac-1?Co mmunityKey=2751b51d-483f-45e2-81de4 faced0a290a\&tab=librarydocuments. Accessed March 16, 2021.

11. Vinson DC, Paden C, Devera-Sales A. Impact of medical student teaching on family physicians' use of time. J Fam Pract. 1996;42(3):243-249.

12. Irby DMB, Judith L. Time-efficient strategies for learning and performance. Clin Teach. 2004;1(1):23-28. doi:10.1111/j.1743498X.2004.00013.x

13. Neher JO, Gordon KC, Meyer B, Stevens N. A five-step "microskills" model of clinical teaching. J Am Board Fam Pract. 1992;5(4):419-424.

14. Cohen DA, Truglio J. T.J., Fitting it all in: an interactive workshop for clinician-educators to improve medical education in the ambulatory setting. MedEdPORTAL. 2017;13(1):10611. doi:10.15766/mep_2374-8265.10611

15. Morrison E. An Objective Structured Teaching Examination (OSTE) for Generalist Resident Physicians. MedEdPORTAL. 2005;1(1):1. doi:10.15766/mep_2374-8265.103

16. Cohen J. A coefficient of agreement for nominal scales. Educ Psychol Meas. 1960;20(1):37-46. doi:10.1177/001316446002000104

17. Burnard P, Gill P, Stewart K, Treasure E, Chadwick B. Analysing and presenting qualitative data. Br Dent J. 2008;204(8):429-432. doi:10.1038/sj.bdj.2008.292 